\title{
Hélio Oiticica, Haroldo y Augusto de Campos: el diálogo velado - La aspiración a lo blanco
}

Gonzalo Aguilar I Universidade de Buenos Aires - CONICET

Resumo: Neste artigo são investigadas as relações entre o artista plástico Hélio Oiticica e os poetas do grupo Noigandres: Décio Pignatari, Haroldo e Augusto de Campos. A partir da correspondência e de algumas obras artísticas e poemas, considera-se a questão do "branco sobre branco" como um ponto de confluência e de experimentação que compartem estes artistas durante a década de setenta.

Palavras-chave: concretismo, Hélio Oiticica, "Branco sobre branco".

En este texto se investigan las relaciones entre el artista plástico Hélio Oiticica y los poetas del grupo Noigandres: Décio Pignatari, Haroldo y Augusto de Campos. A partir de la correspondencia y de algunas obras artísticas y poemas, se considera la cuestión del "blanco sobre blanco" como un punto de confluencia y de experimentación que comparten estos artistas durante la década del setenta.

Brasil é o maior corta-barato que existe; um corpo de leite, corta cualquer onda, menos a nossa, claro! Nunca vi tanta burrice e vulgaridade, por isso prefero pensar em você e amá-la e fascinar-me com tudo o que você é e que nada tem a ver com aquilo: EXEMPLO DE EXCEÇÃo! E cada vez menos gente contato por lá: IRMÃos CAMPOS são dos poucos e de nível que sabemos e 
O eixo e a roda: $v .13,2006$

Disponivel em: http://www.letras.ufmg.br/poslit

escrevi longamente sobre você e tudo o que me veio com sua cartasopro vital tão diferente da morna complacência brasileira de banho de bidê; dá-me arrepios sequer pensar naquilo tudo. Pensemos en nós então. Carta de Hélio Oiticica a Lygia Clark, desde New York, 10.10.1974 ${ }^{1}$

\section{Acefalia}

No es difícil rastrear en los textos y en las prácticas de la crítica cultural brasileña la existencia, muchas veces mal disimulada, de una disputa entre sus dos grandes metrópolis, Río de Janeiro y San Pablo, por ver cuál se convierte en la cabeza del mapa cultural brasileño. En esta lucha, a menudo quedan afuera las ciudades menores que deben correrse al margen para dar lugar a la gigantomaquia carioca-paulista. Ante este espectáculo de lucha por la exclusión mutua que a su vez excluye a los otros, podría postularse otra alternativa: la de pensar Brasil, según la propuesta acefálica de Raúl Antelo, como una confederación. Heredera del legado batailliano, la noción de acefalía se opone a la idea de nación única, encolumnada atrás de la ciudad-capital y ayuda a pensar en un campo plural y abierto que, como querían Oswald de Andrade y Tarsila de Amaral, no comienza en la cabeza sino en la punta del pie. Roteiros y no reterritorializaciones. Lo lúdico antes que lo lúcido, las redes antes que lo jerárquico, la dispersión antes que la acumulación y la concentración.

Todavía no se sabe a ciencia cierta cuánto ha perdido el pensamiento crítico en su obsesión con el enfrentamiento entre Río y San Pablo pero puede hacerse un cálculo aproximado si se piensa en la figura de uno de los artistas más relevantes de la segunda mitad del siglo XX: Hélio Oiticica. Oiticica, quien vivió casi toda su vida en Río de Janeiro, se ha convertido en los últimos años en uno de los pocos artistas latinoamericanos que han ganado reputación internacional, un lugar en los museos y una cotización en el mercado. Sin embargo, un sencillo recorrido por su bibliografía deja ver a este artista apresado dentro de la referencialidad carioca. Ya sea

analizado por Ferreira Gullar, por Ronaldo Brito o por Frederico Morais (cuya calidad crítica no está en cuestión), el arte de Oiticica tendría su momento

1. Lygia Clark - Hélio Oiticica, Cartas, org.Luciano Figueiredo, Prefácio de Silviano Santiago, Rio de Janeiro, UFRJ, 1996. 
fundacional en la ruptura neo-concretista de 1959 y desde entonces no habría dejado de desplegar una estrategia que continúa los lineamientos básicos del manifiesto redactado por Ferreira Gullar y Ronaldo Brito. Este esquema finalista olvida o suprime las profundas transformaciones que se produjeron en la obra del artista durante su estadía en Nueva York, donde vivió más de siete años, y en los últimos años de su vida en Río de Janeiro, cuando proyectó muchísimas de sus obras para ser montadas en San Pablo.

Producto de este planteo se produjo un curioso vacío en el estudio de la obra de Oiticica: el de sus vínculos con los poetas Augusto y Haroldo de Campos, confraternidad prolífica que, desde mi punto de vista, está escamoteada básicamente por la supuesta oposición entre un arte carioca más corporal y subjetivo frente al modernismo frío e intelectual de los paulistas. ${ }^{2}$ Si bien esta oposición no es muy rigurosa teóricamente, la mayoría de los textos críticos tienden a otorgarle implícitamente cierta credibilidad. Esta dicotomía dice muy poco, sin embargo, sobre la obsesión de Hélio Oiticica por perseverar en su programa constructivo o sobre el acercamiento que hizo Augusto de Campos a los todavía más corporales, siempre según estas mitologías urbanas, bahianos del tropicalismo. Ante el lugar común de la glacial racionalidad de los concretos uno no puede dejar de preguntarse dónde estaría la frialdad o la no corporalidad de un poema como las Galáxias o cuál sería la racionalidad cerebral de las explosiones de los Popcretos de Augusto de Campos. Justamente, una de las características de las disidencias de las vanguardias de los años cincuenta fue la brevedad de los enfrentamientos y la disponibilidad de los artistas a modificar o aun abandonar sus programas en función de las nuevas situaciones que se iban presentando.

Después de la ruptura del neoconcretismo, los caminos de Oiticica y los hermanos Campos volvieron a cruzarse, por lo que la postulación de una afinidad estética ya no es el resultado de una operación crítica sino algo que se puede comprobar documentalmente. A principios de los años setenta y ya en Nueva York, Hélio Oiticica recibe, en diferentes momentos, las visitas de Haroldo y Augusto de Campos y de Décio Pignatari. Existe, afortunadamente, un registro de estos encuentros tanto en los textos de Hélio

2. Todo esto, además, sin tener en cuenta que dos miembros que continúan actuando con el grupo "paulista" eran cariocas: José Lino Grunewald y Ronaldo Azeredo. 
como en los poemas de Haroldo y en las cintas que Hélio grabó de sus conversaciones con Haroldo. ${ }^{3}$ Se produce un diálogo intenso que puede rastrearse en sus obras, en sus textos, en sus poemas y, sobre todo, en los obsesivos cuadernos de Hélio, bitácora del artista en el campo de la experimentación y registro minucioso de aquello que iba llamando su atención. Este encuentro entre los hermanos Campos y Oiticica puede ser definido con las hermosas palabras que este último le escribió a Haroldo en una carta del $1^{\text {o }}$ de septiembre de 1974: un "cresço-crescem: genealogicamente e jamais como 'algo que dá em alguma coisa': seria assim como 'algo q gera e se gera em faces-confronto' [...] mútuo scrapear: cada medida verbal é YEs em relação à outra: Yessying SIMULTÂNeO: voilà!: SingultâneO (q termo full of pregnancies não?)". El vínculo no es de deuda ni de subordinación: hay un potenciamiento mutuo, un choque de fuerzas ( to scrap es forcejear), una doble afirmación de singularidades simultáneas que se encuentran en la misma encrucijada. Un encuentro genealógico (Oiticica leía denodadamente a Nietzche por esos años), es decir de sendas embrolladas y garabateadas, de percepión de las singularidades, en un estado de invención. ${ }^{4}$

Para desarmar la supuesta animosidad, indiferencia o distanciamiento entre Oiticica y los hermanos Campos, entre la estética 'carioca' y la 'paulista', basta ver la portada de Navilouca, revista dirigida por Waly Salomão y Torquato Neto, que trae algunos datos novedosos sobre el arte brasileño de principios de los setenta (ilust.1). Organizada como un tablero cuadriculado irregular con las fotos de los artistas que participaron en el número, la portada de Navilouca exhibe los retratos de aquellos a los que sus directores (Waly Salomão y Torquato Neto) consideran los artistas más experimentales de Brasil en ese momento (la revista salió en 1974 pero llevó

3. Buena parte de esta documentación está disponible on line en el excelente sitio sobre Hélio Oiticica de Itaú cultural: www.itaucultural.org.br/aplicexternas/ enciclopedia/ho. Todas las citas de los documentos de Hélio Oiticica, salvo cuando se trata de inéditos (como la correspondencia con Oiticica que tan gentilmente me cedió Augusto de Campos), están tomadas de los documentos de este sitio. Las citas son muy fáciles de identificar mediante el buscador que posee el sitio.

4. Gloso el primer pasaje de "Nietzsche, la genealogía, la historia" de Michel Foucault (1985: 134). 
más de dos años de gestación). ${ }^{5}$ La tapa no es un manifiesto pero pueden leerse en ella las líneas básicas de un programa o de una noción de la cultura que difiere de la estrategias vanguardistas habituales. En primer lugar, los retratados no están elegido de acuerdo a un corte generacional. Sus edades son, por decirlo de alguna manera, escalonadas: desde Lygia Clark (1920-1988), Haroldo de Campos (19292003), Augusto de Campos (1931) y Décio Pignatari (1927), pasando por Hélio Oiticica (1937-1980), Rogério Duarte (1939), Caetano Veloso (1942), Torquato Neto (1944-1972), Duda Machado (1944) y Waly Salomão (1944-2003), hasta llegar a los más jóvenes Iván Cardoso (1952), Chacal (1951) y Luciano Figueiredo (1948). La lógica vanguardista del enfrentamiento generacional o del parricidio es desplazada en función de unas alianzas y agrupamientos que no se corresponden con la juventud o con la irrupción de un grupo en la escena cultural.

En segundo lugar, si bien las fotos son individuales no se produce en el diseño ninguna jerarquización: el espacio creado es el de lo "singultâneo", para utilizar la expresión de Hélio. Las fotos se disponen de un modo azaroso y poco importa que, por ejemplo, Torquato Neto esté en el centro a la izquierda y Caetano Veloso abajo. La individualidad preservada habla de la independencia entre los participantes y el carácter no colectivo -o no coactivo- del proyecto, también está motivada, de todos modos, por cuestiones prácticas: era imposible juntar a los retratados porque se encontraban en diferentes partes del mundo. Aunque la mayoría de los retratados vivían en Río de Janeiro, por ese entonces, Oiticica estaba radicado en New York, Lygia Clark en París, los poetas de Noigandres en San Pablo y Torquato Neto, para el momento en que se publica el número único de Navilouca, ya estaba muerto. La revista, entonces, sostiene cierta extraterritorialidad, una zona común en la que no importan los lugares de producción (como sí pudieron serlo, por ejemplo, en la ruptura de los neoconcretos) sino la posición marginal y experimental, muy acorde con los tiempos posteriores

5. El título Navilouca es una traducción libre de Stultifera Navis, la Nave de los locos que inspiró a Erasmo y a la que Michel Foucault se refiere ampliamente en Historia de la locura en la época clásica. Foucault, además, brindó unas conferencias en Río de Janeiro en mayo de 1973 -es decir, mientras se estaba armando la revista- que después serían recopiladas en el libro La verdad y las formas jurídicas (Buenos Aires, Gedisa, 1980). Los retratados en el primero y único número de Navilouca son Stephen Berg, Iván Cardoso, Chacal, Lygia Clark, Haroldo de Campos, Augusto de Campos, Rogério Duarte, Luciano Figueiredo, Duda Machado, Torquato Neto, Hélio Oiticica, Décio Pignatari, Luiz Otávio Pimentel,Óscar Ramos, Jorge Salomão, Waly Salomão, Caetano Veloso. 
al endurecimiento del régimen militar, después de la promulgación del AI-5 en 1969.

Genealogía embrollada, singultaneidad y extraterritorialidad: esas son las condiciones en las que se producen algunos de los encuentros de principios de los setenta, entre ellos el de Hélio Oiticica con los poetas del grupo Noigandres. En sus sucesivas obras conjuntas, ellos trazan un nuevo mapa que necesita de cartógrafos que no se sometan a ninguna de las rencillas producidas por las mitologías urbanas existentes.

\section{Genealogía de un encuentro}

Los contactos entre Hélio Oiticica y los hermanos Campos pueden retrotraerse a la época de las primeras batallas concretistas. En el reportaje "O 'Rock'n Roll' da poesia" que la revista O Cruzeiro hizo sobre los debates desarrollados en la UNE en 1957 sobre arte concreta, se reproduce una foto que muestra a Haroldo de Campos discutiendo con el dedo en alto mientras, a un costado, sentado en su butaca, se encuentra el jovencísimo Hélio Oiticica, quien mira hacia adelante (ilust.2). Después, la ruptura entre el concretismo y el neoconcretismo, en 1959, los colocó en grupos opuestos. Mientras los poetas del grupo Noigandres sostenían que la poesía concreta debía avanzar en una fase matemática de la composición, Ferreira Gullar, en su manifiesto, defendía la sensibilidad y la trascendencia y exponía su teoría del no objeto. ${ }^{6}$ Las ideas expuestas por Gullar en el conocido manifiesto les permitió avanzar a los artistas plásticos Lygia Clark, Hélio Oiticica y Lygia Pape en una actividad que excedía la noción de marco y de obra, y que los arrojó súbitamente en las dimensiones de lo háptico y lo abyecto. La teoría del no objeto traía aparejada una crítica de la visualidad y de los límites del arte que impulsaba a los artistas a incluir aquello que amenzaba su identidad y que configuró lo que podríamos denominar un abyecto anestético como, por ejemplo, la tierra utilizada en algunos Bólides de Hélio.

6. Dice Ferreira Gullar: "O não-objeto não é um antiobjeto mas um objeto especial em que se pretende realizada a síntese de experiências sensoriais e mentais: um corpo transparente ao conhecimento fenomenológico, integralmente perceptível, que se dá à percepção sem deixar resto. Uma pura aparência" (citado en Amaral 1977: 85). 
Aunque esta escisión fue decisiva para la actividad posterior de los artistas neoconcretos, a menudo se olvida que el manifiesto concreto que anunciaba la "fase matemática da composição" se desintegró rápidamente: primero con la posdata que anunciaba una lírica participante e, inmediatamente y de un modo mucho más categórico, con la inclusión de elementos que contradecían o aniquilaban ese programa. Los popcretos de Augusto de Campos, presentados en la galería Atrium en 1964, trabajaban con lo aleatorio y con materiales de desecho (básicamente, recortes de diarios y revistas pero también marquillas de cigarrillos o envoltorios de papel). Hay un cuestionamiento del poema - de hecho, en muchos casos se trata de poemas sin palabras -, y lo abyecto anestético - las letras de los periódicos - no es circunstancial sino configurador. El mismo año, Haroldo de Campos publica las primeras Galáxias en la revista Invenção: las palabras inicial del poema pueden ser leídas como el decreto de muerte de la poesía concreta: "e começo aqui e meço aqui este começo". Aparición del sujeto, del cuerpo, del lugar: el poeta comenzaba una aventura que terminaría recién en 1976 (fecha de la última galaxia) y que, simplemente, ya no puede ser leída desde el concretismo. Es más: el proyecto de este poemario contemplaba la inclusión del afuera, algo totalmente ajeno a las pretensiones matemáticas de los poemas de fines de los cincuenta: los poemas de Galáxias no sólo se escribían a partir de las circunstancias y lo aleatorio, sino que su estructura abierta admitía un recorrido no previsto que fue, de hecho, lo que sucedió durante su larga y lenta gestación. "Uma insinuação épica que se resolveu numa epifânica", como escribió el propio Haroldo dando cuenta del inicio del proyecto en los promisorios sesenta y de su conclusión una década después, en tiempos de desencanto.

La dimensión de lo abyecto, entendido como aquellos materiales que el arte consideraba desechos pero que a la vez amenazaban a su propia forma, ingresan en la obra de Oiticica y de Haroldo a partir del 'descubrimiento' que hacen de un mismo artista: Kurt Schwitters. ${ }^{8}$ Leído como un dadaísta-

7. Tomo la definición del concepto de Afuera del trabajo de Gilles Deleuze sobre Foucault: "La exterioridad sigue siendo una forma, como en La arqueología del saber, e incluso dos formas exteriores una a otra, puesto que el saber está hecho de esos dos medios, luz y lenguaje, ver y hablar. Pero el afuera concierne a la fuerza: si la fuerza siempre está en relación con otras fuerzas, las fuerzas remiten necesariamente a un afuera irreductible, que ya ni siquiera tiene formas, que está hecho de distancias incomponibles gracias a las cuales una fuerza actúa sobre otra u otra actúa sobre ella” (1987: 115-116). 
constructivista, Schwitters ya había aparecido en el manifiesto "nueva poesía: concreta", redactado por Décio Pignatari en 1956 (Pignatari 1975: 42), y en el primer artículo de Haroldo publicado en el Jornal do Brasil el mismo año: "Kurt Schwitters ou o jubilo do objeto", después incluido en $A$ arte no borizonte do provável (São Paulo, Perspectiva, 1969). En Schwitters, tanto Oiticica como Haroldo encuentran la apertura a cualquier objeto, aun los desechos: una materialidad que trastorna las relaciones del color y la palabra con la forma y las arroja a una nueva intemperie. Schwitters (quien trabajaba con todo lo que se encontraba en el camino pero con lineamientos constructivos) está en el origen de los Bólides de Hélio y en las Galáxias de Haroldo de Campos, proyectos que se comienzan a articular a principios de los sesenta, en consonancia con los profundos cambios sociales y políticos que se estaban viviendo entonces en Brasil. El impacto del afuera (lo impensado, lo aleatorio, lo informe, lo abyecto) sacude unos programas artísticos que, en sus inicios, se habían articulado alrededor de las ideas de construcción, conciencia y planeamiento. Esta tensión, este choque, marcará las obras del pos-concretismo hasta bien entrados los años setenta, y la recuperación de Schwitters, quien había sido reivindicado tempranamente pero que después había sido eclipsado durante la fase ortodoxa, hay que entenderla como un retorno de lo reprimido, de aquella materialidad bullente (como la de Poetamenos) que había sido dejada de lado en función de las formas orgánicas, proporcionadas y matemáticas.

Sin embargo, este encuentro alrededor de Schwitters habla más de las aporías a las que se había enfrentado el proyecto constructivo en las artes plásticas o en poesía antes que de una actitud común o de una relación causal entre el artista carioca y los poetas paulistas. Es, si se quiere, el testimonio de que enfrentaban un impasse similar que trataron de resolver recurriendo a soluciones constructivas radicales como la de Schwitters. Para que la coincidencia se transformara en una implicación recíproca, en un "mútuo scrapear", hay que esperar hasta principios de los setenta cuando, una vez fuera del país, Oiticica comienza a hilvanar nuevas amistades y nuevas afinidades

\footnotetext{
8. De hecho, el ensayo "Hélio Oiticica: el músico de la materia" que Haroldo de Campos (2006) escribió en homenaje a Hélio comienza con una evocación de Kurt Schwitters.

9. En mi libro sobre concretismo, desarrollo la cuestión del retorno de lo reprimido a partir de una lectura de Poetamenos (Aguilar 2005).
} 
estéticas. La distancia neoyorquina le permite también a él, que era carioca hasta la médula, observar líneas experimentales que antes no había percibido. Sin duda, su acercamiento a algunos jóvenes vinculados al tropicalismo, principalmente Torquato Neto y Waly Salomão, fue una de las vías que lo llevó a la poesía de Augusto y Haroldo de Campos y de Décio Pignatari. En el caso de Augusto, fue Torquato el que llevó a Hélio una vez a su casa y donde se conocieron por primera vez (después, se encontraron una vez más en Nueva York). Con Haroldo y Décio, en cambio, los encuentros fueron más frecuentes a lo largo de los años setenta (a propósito de la muerte de Oiticica y de su velorio, Décio publicó un emotivo texto que incluyó en Letras, artes, mídia). Desde entonces, a tal punto comenzó a ocuparse Oiticica de la obra de los poetas de Noigandres que se puede afirmar que de no comprenderse los alcances y las sutilezas de esta lectura varios elementos de la obra que desarrolló en los setenta permanece oscura. Y, complementariamente, también puede afirmarse que esto no solo repercute en su obra sino que sus insights lúcidos e instigantes abren una línea de interpretación diferente de las poéticas de los hermanos Campos. El choque genealógico que protagonizan Hélio Oiticica y Haroldo de Campos señala una serie de obsesiones y orientaciones comunes, sin perder su singularidad, que definiré a partir de la noción de trazo blanco.

\section{O novo guesa errante}

Nova York, quando a pólvora prateada do
sonbo já virara rastro de fuligem Décio Pignatari: "Hélio e a arte do agora"

Hélio Oiticica e Waly Salomão não paravam de falar sobre Haroldo e Augusto de Campos como se fossem os representantes de deus na terra.

En 1970, Hélio Oiticica aprovecha la obtención de la beca Guggenheim para abandonar el clima opresivo que se vivía en Brasil y trasladarse a Nueva York, donde se queda hasta 1978. El mismo año en que llega a la ciudad de los rascacielos participa en la muestra colectiva Information que se realiza en el MoMA. Aunque esto significaba entrar en el circuito del mercado artístico, después de esta muestra Oiticica abandona el mundo de 
las exposiciones de arte y se dedica básicamente a escribir sin parar en sus notebooks y a desarrollar unos films dentro del programa que él denomina "quase-cinema". En 1972, comienza el rodaje del film Agripina é Roma-Manhattan por las calles de la ciudad con un roteiro muy sencillo: usar como locaciones los lugares mencionados en "O Inferno de Wall Street" del poema O Guesa Errante de Joaquim de Sousa Andrade, más conocido como Sousândrade (1833-1902). En uno de sus textos fechados en abril de 1972, Hélio señala los lugares tomados del "book H/A CAMPOS":

a) photos as in sup.8 shorts at TRINITY CHURCH

b) fragments of NEW YORK STOCK EXCHANGE

c) BATTERY PARK shots

[...] H. CAMPOS \& Company doing WALL ST expedition

g) TRINITY CHURCH cemetery: enlarge photo of word BODY showing BOD (exclude $\mathrm{Y}$ in print) ${ }^{10}$

La analogía entre la Roma antigua y la New York de mediados de siglo XIX ya se anuncia en "O Inferno de Wall Street" en el parágrafo 71: "Roma começou pelo roubo; / New York, rouba a nunca acabar". Pero es en el parágrafo 129 que Sousândrade crea esa superposición entre la isla y la capital imperial de la Antigüedad que inspiraría el título del film inacabado de Hélio además de uno de sus poemas visuales (ilust.3):

129 (Outros alagados salvando-se na coluna 666 do templo de Kun:)

- Agripina é Roma-Manhattan

Em rum e em petróleo a inundar

Herald-o-Nero aceso facho

e borracho,

Mãe-pátria ensinando a nadar!...

Con unos amigos y actores del underground neoyorquino (entre los que se encontraba el legendario Mário Montez) Oiticica llegó a filmar en super-

10. La aclaración de "excluir" la "y" es curiosa ya que Sousândrade usa la palabra "bod" (en vez de "body") porque la extrae de una lápida del cementerio de Trinity Church en la que se lee "HEAR-LYES-THE-BOD OF-RICHARD-CHURCH". Ver CAMPOS 2002: 350 y 403 . 
8 algunas escenas aunque, finalmente, nunca terminó la película. Sousândrade fue - junto con Waly y Torquato - el otro eslabón en la cadena que unió a Oiticica con los poetas concretos. ${ }^{11}$ La violencia ejercida sobre el lenguaje, la creación permanente de compuestos de palabras muchas veces ininteligibles, la reverberación de sentidos por medio de los encuentros fortuitos o forzosos recorren las Galáxiasy las invenciones lingüísticas de Hélio que Luciano Figueiredo (2002) propone llamar poemas. Como en "M'way ke", inscripción del parangolé dedicado a Haroldo, donde se entreveran el camino y el despertar bajo la invocación del Finnegans de James Joyce (ilust.4). O como en la obra "Topázion-flor (dedicada à Haroldo de Campos, 20 de março, 1975)", que toma su nombre de un verso del poema Harpas douradas del propio Sousândrade. ${ }^{12}$

En uno de los textos que le dedicó, "Parangol(h)elium", ${ }^{13}$ Haroldo construye un escenario - se trata de un poema dramático - en el que el artista carioca hace su aparición para ascender y disolverse en un temblor de aire. Se trata de un triple escenario formado por el teatro nô, el "Inferno de Wall Street" de Sousândrade y la "dark-tower" de Childe Harold de Byron, libro que - como se sabe - fue muy influyente en el escritor maranhense (además, Harold remite obviamente al propio poeta). El poema, originalmente impreso con letras blancas sobre fondo negro, dice así:

\section{Parangol(b)elium}

(miniteatro nô à maneira de sousândrade / cena única /

topo de um arranha-céu em Manhattan)

heráclito, ho skoteinós (dark-minded), falando por gregueiras:

hélios gàr oukh huperbésetai métra

ei dè mè erinúes min díkes epíkouroi

exeurésousin

11. En una carta a Haroldo de 1ํ de septiembre de 1974, Hélio recuerda "nossos passeios kitsch-sousândrinos por Goтнам CiтY".

12. Se trata de una foto compuesta con un collage de objetos entre los que se encuentran un libro sobre la cocaína, una foto de los actores Paulo Cesar Suply y Cristina Nazareth tomada del film Piratas do Sexo voltam a matar (1971) de Ivan Cardoso.

13. Poema de Haroldo de Campos reproducio en Cardoso (2002). 
O eixo e a roda: $v .13,2006$

Disponivel em: http://www.letras.ufmg.br/poslit

childe harold (exsurgindo de sua dark-tower e intraduzindo):

o sol não desmesura
ó eríneas
servas de díke
justiçadoras

o parangoromo pluriplumas se heliexcelsa helinfante celucinário até decéuver-se no céu do céu

Los versos reescriben dos textos: un fragmento de Heráclito ("El sol no traspasará sus medidas; si no las Erinias, asistentes de Dike, lo descubrirán”) reproducido en griego y en portugués ${ }^{14}$ y el final de la pieza de teatro noh Hagoromo del escritor japonés Zeami ("excelso / dissolvido no céu do céu"). "Parango(h)elium" no es sólo un homenaje: una lectura atenta revela un nuevo punto de vista sobre la obra-vida de Oiticica. En el título, el poema juega con el doble sentido del nombre Hélio, que puede ser Hélios, el dios griego del sol, o helio, el gas más liviano existente que por su volatibilidad apenas se encuentra en la atmósfera terrestre. ${ }^{15}$ Posteriormente, se reproduce una frase de Heráclito en griego transcripto a caracteres latinos y la transcreación que hizo Haroldo. Como observó el propio Oiticica, en la lectura que hizo del poema (carta del $1^{\text {o }}$ de septiembre de 1974), "sonorear antes que entender", una vez más poniendo la materialidad del lenguaje por sobre la preeminencia tradicional del significado.

14. En "Heráclito revisitado" de A educação dos cinco sentidos, Haroldo transcrea fragmentos de Heráclito entre los que se encuentra este pasaje.

15. La relación entre su nombre y el helio había sido hecha por el artista cuando tomó como su emblema la frase "Call me helium" que pronunció Jimi Hendrix en una entrevista. La frase completa del guitarrista norteamericano es: "I have this one little saying, when things get too heavy just call me helium, the lightest known gas to man." 
La frase de Heráclito es a menudo interpretada como la postulación que hace el filósofo de una ley inexorable (la dike) por sobre el mundo visible, donde "la guerra es la madre de todas las cosas". Ni aun el sol puede transgredir esa ley y penetrar en el mundo arcaico y oscuro de las Erinias que le está vedado (NestLe 1981: 62). Dos consecuencias pueden sacarse de esta conexión Heráclito / Hélio (nótese que en el nombre Heráclito puede leerse anagramáticamente el nombre Hélio ${ }^{16}$ ). Por un lado, la necesidad de abandonar toda la lógica de la transgresión con la que a menudo se piensa la obra de Oiticica, como si sus trabajos tuvieran como principal interés suspender temporariamente una ley o revelar el carácter represivo de una sociedad. Las Cosmococas podían suscitar un escándalo pero nada le interesaba menos a Oiticica que extraer fuerza de ese escándalo para la recepción o el disfrute de su instalación. Antes bien, durante los setenta, Hélio es un "artista de la afirmación" y del goce, como él mismo llegaría a reconocerlo después de la lectura de Nietzsche y la filosofía de Gilles Deleuze. ${ }^{17}$ Su hacerno vale por las prohibiciones de las Erinias: el helio sube, se evapora, se diluye (el "deceuverse") "no céu do céu".

La segunda consecuencia que puede extraerse del poema de Haroldo consiste en el carácter de goce o éxtasis que encuentra el cuerpo de Hélio (goce masoquista si se quiere) en su propia disolución (algo que ya estaba en la "desaparición elocutoria del yo" de Mallarmé). ${ }^{18}$ Este goce encuentra su palabra en el crelazer (otro término inventado por Hélio) o en el edén, "un hebraísmo que, no por casualidad, significa delicia" (CAmpos 2006: 210). Eden, la instalación que Oiticica presentó en la Whitechapel en 1969, y Éden, libro de Haroldo de Campos editado póstumamente, son dos lances de dados del mismo impulso. $\mathrm{Ni}$ uno ni otro están construidos contra Babel sino que le dan espacio a la "epifanía" y al "júbilo", en lenguaje de Haroldo, o a los "éxtasis discontinuos", en palabras de

16. En A operação do texto (1976), Haroldo de Campos publica un ensayo sobre los anagramas de Saussure en el que analiza los alcances de la lectura anagramática en poesía.

17. Ver el documento del Manifesto Caju de 1979 en el que Oiticica cuenta cómo Silviano Santiago le acercó la lectura del Nietzsche y la filosofía de Deleuze.

18. No puedo dejar de pensar aquí en las ceremonias de las Cosmococas que analicé en Aguilar (2006) y en los análisis de Leo Bersani, quien habla, en los textos de Freud, de una represión "of the masochistic, nonnarrative, timelessly replicative grounds of the sexual" (1986: 113) 
Oiticica. ${ }^{19}$ Un paraíso de la inmanencia: de los cuerpos, de los materiales, de la energía. En otro de los textos reveladores que Haroldo escribió sobre el artista carioca, se lee: "Nada tienen, sin embargo, estos "Parangolés" que evoque una conciencia pecaminosa. Son paramentos laicos, celebran lo paradisíaco en el instante-vida" (CAmpos 2006: 215). Un edén sin Dios ni Evas ni Adanes (no hay en Éden de Oiticica ninguna remisión icónica al paraíso). La reflexión de Haroldo me gustaría leerla así: ahora que Dios ha muerto, ahora que ya no hay deuda que pagar, hay que inventar el Edén. O, en términos más filosóficos, la forma ya no viene del primer motor, por lo tanto sólo se puede trabajar con la energía que irradia la materia. En los reveladores textos que ha escrito sobre lo sublime, Jean-François Lyotard sostiene que el empuje oscuro y vago de la materia tiende, cuando se expresa como informe, a deshacer o a cuestionar el dispositivo metafísico del principio de finalidad según el cual opera la forma (1998: 143).

Como observó Haroldo a propósito de Éden, hay entonces un retorno del "paraíso" pero en condiciones absolutamente modernas: sin nostalgias ni retrocesos, el paraíso es una consecuencia del hacer humano. ${ }^{20}$ En la poesía de Haroldo, este retorno reactualiza el esquema tripartito medieval (paraíso, infierno, purgatorio) en el que el purgatorio hace de pasaje o, para decirlo con un término teorizado por Derrida, de himen. El purgatorio es el trazo, lo que pasa entre, barra de disyunción y unión: entre la luz y la oscuridad, el edén y el infierno, Helios y el hades. "O purgatório é isso: / entre/inter-" escribió Haroldo en un poema "A educação dos cinco sentidos". Porque la cuestión es, más que el Edén, instalarlo o escribirlo - desde el purgatorio de la modernidad. Ya el poeta Auden había hablado de la importancia de imaginar cómo sería el paraíso y Ezra Pound había terminado sus Cantos con estos versos:

19. Éden (Um tríptico bíblico) de Haroldo de Campos contiene dos fragmentos del Génesis ("A Astúcia da Serpente" y "Babel") y una traducción de "O Cântico dos Cânticos".

20. Recordemos que esta operación ya estaba en Sousândrade, que decidió ubicar su infierno nada menos que en Wall Street. 
He intentado escribir el Paraíso.

No os mováis

Dejad hablar al viento

ése es el Paraíso

"Escribir el Paraíso": ¿pero es eso posible? En Haroldo y en Hélio, se trata de trabajar con la "arquimemória assombrada desse exílio pós-edénico" (CAmpos 2004: 48). Inscribir un trazo, pero más que nada un trazo que deje aflorar esa archimemoria (arquimemória), ese origen que, como quería Walter Benjamin, está localizado "en el flujo del devenir como un remolino que engulle el material relativo a la génesis” (1990: 28). ¿Cuál es el pequeño intersticio, el etéreo hueco, por el que irrumpe el origen en "Parango(h)elium"? L $b$ entre paréntesis, que no sólo es la letra inicial de los dos artistas, sino la "navalha de éter" de la galaxia que Haroldo le dedicó a Hélio, la letra aspirada que no se pronuncia, donde la boca sólo impulsa el viento, como quería Pound. Es el blanco sobre blanco de la escritura de signos. La (h) entre paréntesis es el trazo blanco de este poema.

Ya en la conversación que mantienen Haroldo de Campos y Hélio Oiticica en Nueva York el 27 de mayo de 1971, la cuestión del blanco recorre casi todos los diálogos. Disolución del blanco "no céu do céu", como traduce Haroldo en Hagoromo, la experiencia es aplicada a los Ninhos y al parangolé blanco que el propio Hélio le dedicó al poeta de Noigrandres. Se trata, como dice Haroldo en una de las grabaciones, de una "busca de uma coisa que fica entre o visível e o invisível; é alguma coisa que é entre, não é isso ou aquilo, está entre os dois”. "Toda esta relación de a tres (Hélio/ Haroldo/hagoromo) está desarrollada en la composición de una de las Galáxias ("tudo isto tem que ver"), que comienza con el suplicio chino estudiado por Georges Bataille en Las lágrimas de Eros y termina con la disolución en el cielo de la capa de la obra Nob (otra vez: no hay exclusión absoluta entre la formación babélica y la edénica sino grados, transiciones, diferencias de intensidades). Escrita a fines de 1969, tiene una gran importancia porque es la que Haroldo le lee a Hélio Oiticica en la conversación que mantuvieron en Nueva York en 1971 y que fue grabada en una cintas que

21. La conversación, que fue editada en la revista Flor do mal en los años setenta, puede encontrarse en el sitio ya mencionado. 
Haroldo bautizó Héliotapes. ${ }^{22}$ Al final de este poema, Haroldo transcribe el coro final de su traducción de la pieza de teatro noh Hagoromo de Motokiyo Zeami (1363-1443) que le dedicó a Oiticica. Aunque Haroldo comenzó a traducir la pieza en 1960, recién en 1969 tradujo el coro final y sólo en 1991 la editó en libro: Hagoromo de Zeami (O charme Sutil). La galaxia pone en escena dónde se inscribe este trazo blanco: en el cuerpo que primero es sometido a un recorrido quirúrgico y que al final migra hacia las alturas. El cuerpo es, aquí, esa materia oscura que según Lyotard - empuja desde abajo, ya sea como enigma pasivo (en el recorrido quirúrgico) o como elemento activo (cuando danza), poniendo en cuestión la preeminencia de la forma en tanto principio espiritual. Este disolverse del cuerpo no es su eliminación sino su epifanía.

22. Transcribo un e-mail que me envió Raúl Antelo con una sugerente y fascinante lectura del término: "Yo leería el término heliotapes no sólo en inglés, sino bárbaramente, y en masculino, como "los caminos del primitivo Hélio". Hélio es para Haroldo el Chico Antonio de Mário de Andrade, el que hace lo que él no se atreve a hacer. Un indio. Tapes es nombre de tribu indígena que habitaba el Rio Grande del Sur. Es nombre que los bandeirantes le dan a esos pastores nómades del sur, emparentados con los quichuas y la coca. En la Wikipedia se lee lo siguiente: "Os povos pré-históricos do município de Tapes eram os índios Patos, de cultura Guarani, um ramo dos Quíchuas do [...] Relatos da época diziam que os indígenas eram imorais, pois não tinham vergonha de mostrar suas genitálias. Os que se recusavam a vestir-se eram condenados pelos Tribunais da Santa Inquisição que atuaram no Brasil Colônia [...] Na linguagem dos indígenas, Tapes era caminho, trilha para o mar, para a Europa, onde afinal os jesuítas tinham suas pátrias, credos e possibilidades de manter comércio. Era zona de Tape o atual estado do Rio Grande do Sul. Com o estabelecimento dos jesuítas nas reduções gaúchas, Tape passou a ser dali ao mar. Os nativos do local eram índios do caminho (Tapejaras, Tapes) [...] O termo Tape deve ter sido assimilado pelo português (ganhando o plural) e designado lugar de caminhos". O sea que, en primer lugar, "tapes" es un primitivo que le hace puente o compensación al Guesa de Sousândrade, otro bárbaro en el Asia, como Bartleby. Además, acordate que Haroldo está en su fase de Morfologia do Macunaíma y que en "Improviso do mal da América", poema de la época de Macunaíma, Mário dice sentirse blanco solo blanco con un grito imperioso de blancura, cosa que siempre se le interpretó como arianismo, cuando en realidad es la noción de polifonía etnica y cultural, superposición de todas las voces/colores que da blanco como síntesis. Como en la rapsodia. Que se baila. Ya ves que de uno a otro lo real se impone. Asi que héliotapes se puede oir en otra lengua (Derrida: la deconstrucción es plus d'une langue) y son como quipus, como obliteraciones de la escritura indispensables al surgimiento de la voz, es decir, del cuerpo". 
Otras obras podrían ser citadas como base documental para el estudio de las relaciones entre Hélio Oiticica y los poetas paulistas. La cosmococa número cuatro, titulada Nocagions, está dedicada a los hermanos Campos. Es la única que no trabaja con rostros humanos y proyecta, además del equipamiento habitual de navajas y tubitos de metal, imágenes del libro Notations de John Cage (de tapa blanca) sobre el que se esparcen, entre el orden y el caos, líneas de cocaína. ${ }^{23}$ El blanco se convierte en un sinónimo de éxtasis y de aprensión de lo inconmensurable (o lo "cósmico"). Otra obra que utiliza un poema de Haroldo de Campos es el Penetrável FILTRO que reproduce, dentro de unas carpas coloridas, grabaciones de lecturas de Galáxias de Haroldo y de The Making of Americans de Gertrude Stein. Entre los proyectos no realizados, se encuentran algunas anotaciones sobre una adaptación fílmica de Poetamenos. Sin embargo, la inclusión más curiosa es la que Hélio lleva a cabo en su proyecto E PET C LO (la palabra "espectáculo" distorsionada), que deja ver el tipo de mezclas que hacía Hélio y el lugar que les asignaba a los poetas paulistas. El proyecto está fechado el 10 de octubre de 1972 y está programado para ser realizado en la Universidad de São Paulo con la colaboración de Walter Zanini. A partir de la propuesta "O espetáculo não é espetacular / O espetáculo é não-espetacular" se suceden las músicas de los Rolling Stones ("Jumpin' Jack Flash", "Live with me"), João Gilberto ("Chega de Saudade"), un samba a elección, Jimi Hendrix ("Voodoo Chile") y se invita a Haroldo de Campos y a Augusto de Campos a improvisar unos textos, a bailar y a incitar a los participantes a bailar también, en una danza que termina con todos acostados en el suelo con el pecho descubierto. Retorna en esta obra el tema de la desnudez y la idea de Oiticica de que los poetas de Noigandres la habían prefigurado en sus poemas a partir del vacío, de los blancos de la página, de la materialidad de las palabras, del cuerpo del poema.

23. En una carta inédita que Hélio Oiticica le envía a Augusto de Campos se lee: "augusto, fue genial que me hayas mencionado el libro de cage, notations: lo compré y es realmente increíble, de una riqueza sin fin, cósmico, con un montaje fantástico; he leído mucho silence también, libro con el que siento una afinidad increíble. la construcción de esos libros son obra de genio" (carta del 16 de octubre de 1971). Notations es una compilación que hace John Cage de partituras de diversos autores que contienen nuevos sistemas de notación musical y que el propio Cage comenta siguiendo el sistema del I-Ching. El título de la obra de Oiticica, Nocagions, juega con la negación y el significado de "cage" (jaula) en inglés, mimetizándose con el título Notations. 
O eixo e a roda: $v .13,2006$

Disponível em: http://www.letras.ufmg.br/poslit

\section{La danza de los velos}

Le blanc souci de notre toile

"Salut" de Mallarmé

El cuerpo que posa para la foto está quieto. De pie y con los brazos ligeramente abiertos tiene la mirada algo perdida. Viste un parangolé absolutamente blanco que es como un paralelogramo colocado sobre su cuerpo, cuyas formas se llegan a ver detrás de la tela transparente (ilust.5). Esta idea de transparencia se hace mucho más evidente en la foto en la que ya no se muestra a Luis Fernando sino a Omar quien viste la misma capa: la foto del modelo está tomada con una fuerte luz desde atrás que dibuja los contornos de sus piernas y de sus brazos. A diferencia de las otras fotos sobre parangolés que muestran cuerpos en movimiento, acá el paño parece fijo y sólo se pliega, blanco sobre blanco, con las manos. Estrategia no para vestir sino para poner el cuerpo al desnudo, el trazo blanco aparece aquí para ocultarse él mismo mientras revela otra cosa. Es el parangolé P30 capa 23 "m'way ke" y fue dedicado a Haroldo de Campos (ilust.Ø).

Este parangolé es, curiosamente, el único cuya datación no se vincula con un momento preciso y cuya composición se extiende durante siete años. Es como si la Capa 23 construyera, a lo largo del tiempo, una arjé (¿una arquimemória?) de las otras capas o una suerte de núcleo que exige ser leído en otro plano que el de las capas de colores. Fechado entre 1965 y 1972, el parangolé tiene un momento de composición y, siete años después, otro de revelación, cuando Oiticica toma las fotos que le envía a Haroldo de Campos en una postal con la dedicatoria: "Para Haroldo, hagorômico em homenagem, 3.9.72". Haroldo colocó esta imagen - otra foto en la que el actor Luis Fernando luce el parangolé - en su libro Hagoromo de Zeami (O charme sutil) publicado en 1991 (ilust.7).

Esta obra se vincula con otra (el parangolé P31 capa 24) que Oiticica le dedica a Augusto de Campos en una tarjeta postal que le envía el 30 de diciembre de 1972 (ilust.8). ${ }^{24}$ El interés por el blanco difiere del de las

24. La carta está inédita pero me ocupo de ella en mi ensayo "La escritura blanca: encuentros de Augusto de Campos y Hélio Oiticica" que será publicado en la revista Mnemosyne. 
otras capas que giran - generalmente - alrededor de los naranjas y los rojos. El parangolé 31 forma una cinta de Moebius alrededor del cuerpo de Jeff (el modelo) y exige un movimiento de las manos (como el dedicado a Haroldo, la remisión a la escritura radica en la importancia dada a las manos). Además, ambos parangolés no tienen que ver con los cuerpos en movimiento sino con los cuerpos en reposo, o para decirlo con las palabras del crítico Denis Riout, se trata de un "reposo dinámico". El pliegue es fundamental en esa capa que no se despliega según curvas vinculadas con el viento y el movimiento del cuerpo, sino por los plegados rectos realizados por la mano.

Ya en sus Bilaterales de 1959, Oiticica se había interesado por el trabajo con el blanco. En un texto escrito en 1962, "Cor, tempo, estrutura", Hélio Oiticica hace varios señalamientos sobre los colores y sus características intrínsecas. Liberando al color de asociaciones simbólicas o psicológicas, el artista carioca los define por su refracción a la luz. Los denomina, de hecho, "cores-luz': blanco, amarillo, naranja, rojo-luz que son, justamente, los colores que está usando en esos momentos en la expansión espacial de sus Bilaterales:

O branco - escribe Oiтicica en "Cor, tempo, estrutura" - é a cor-luz ideal, síntese-luz de todas as cores. É a mais estática, favorecendo assim, à duração silenciosa, densa, metafísica. O encontro de dois brancos diferentes se dá surdamente, tendo um mais alvura e o outro, naturalmente mais opaco, tendendo ao tom acinzentado. O cinza é, pois, pouco usado, porque já nasce desse desnível de luminosidade entre um branco e outro. O branco, porém, não perde o seu sentido nesse desnível e, por isso, ainda resta ao cinza um papel em outro sentido, de que falarei quando chegar a esa cor. Os brancos que se confrontam são puros, sem mistura, daí também sua diferença da neutralidade cinza (1986: 45).

El blanco es un espaciamiento del tiempo y, como lo es en todo el concretismo, una negación de los significados y de los temas: es la duración pura y el color-arjé del cual salen todos los colores y que suspende la llegada del trazo. Pero si el blanco es origen, una vez que surge el pliegue o el trazo ya es la posibilidad del sentido, "la entre-abertura espaciada, el abanico que forma el texto", en palabras de Jacques DerRida (1975: 378). Este trazo abre

25. Denys Riout: La peinture monochrome (Histoire et archéologie d'un genre), Nîmes, Jacqueline Chambon, 1996, p.47. 
una tercera posibilidad del blanco: su concreción sensible (blanco sobre blanco) en la cocaína, en la nieve, en la tapa del libro de John Cage, en la obra de Malevitch, en los espacios de Poetamenos y, por lo tanto, como aparición de la desaparición ("num poro entre visto e invisto onde o visível gesta" de las Galáxias), o la finitud que se convierte en infinitud, otra vez en palabras de Derrida (1975: 379). El blanco es trazo y borradura, transparencia y membrana, cuerpo y luz o, mejor, cuerpo-luz. El blanco no es aquí el inicio ("sur le vide papier, que la blancheur défend", Mallarmé) sino el éxtasis, lo excelso, que se logra después de un trabajo. "O centro de gravidade da meditação. O átomo puro. A paz", como escribe Murilo Mendes en "Texto branco". Pero vamos al origen de todo: Blanco sobre blanco de Kazimir Malevitch.

La referencia al pintor Malevitch era común entre todos los artistas que participaron del concretismo. Según el testimonio de Augusto de Campos:

Meu primeiro contacto com os quadrados de Maliévitch se deu em 52, nas conversas com os pintores concretos (Cordeiro, especialmente, que era teórico tinha grande capacidade de formulacão). Embora a vanguarda russa não estivesse presente nas primeiras bienais (as autoridadeas soviéticas as relegavam aos porões dos seus museus), comprei na ocasião dois números da revista francesa Art d'aujourd'bui, de junho de 1952 e julho de 1953 (que ainda tenho). No primeiro, ele comparece com alguns dos seus trabalhos no artigo "De la figuration à l'abstraction. Quelques documents pour aider à mieux comprendre le passage de la ligne" réunis para R.V. Gindertaël. No segundo, há um estudo mais longo e completo "Les idées de Malevitch" por Julian Alvard, que me impressionou muito. Entre as ilustrações (todas em preto e branco), o quadrado preto de 1913, ocupando todo o quadro, e um dos "branco sobre branco" de 1916. Juntamente com Mondrian, e os concretos paulistas, é a base plástica do Poetamenos.

La lectura de Malevitch configura un típico fenómeno de lo que Haroldo de Campos denominó "lectura sincrónica-retrospectiva" que coloca en primer plano a un artista que, a lo largo del siglo, no había tenido la misma fortuna que Klee o Kandinsky, para no hablar de los canónicos surrealistas en materia de vanguardismo. Esta lectura privilegió - en una típica visión modernista - los aspectos materiales y autorreflexivos (la esencia de la pintura) antes que las inclinaciones místicas o la puesta en escena de lo sublime. Malevitch era más visto como constructivista y como crítico de la representación que como un suprematista que concebía sus obras en el cruce 
de la sensibilidad y lo absoluto. Sin embargo, a principios de los setenta, se produce otro retorno de Malevitch, ahora en un contexto en el que lo blanco remite al cuerpo, al éxtasis, a lo sublime. Es en este retorno de Malévitch que se produce la lectura que hace Oiticica de Poetamenos, poemario de Augusto de Campos que se reedita en 1973 con motivo de cumplirse treinta años de su primera edición. En un proyecto de obra de los Newyorkaises fechado el 4 de junio de 1974 (ilust.9), escribe:

"Body-filmic / I think (and homage) of / Augusto de CAmpos / and Poetamenos and the / color-lettered words as / filmic letters-quality / turning the white background / as filmic space: CAMPOS/MaLEviTCH / are previewers of the void in concept of nakedness: / foretellers: / angels on WHITE ON WHITE / abolition of moral judgements: / BODYinhibitions: naked? what did it use to be?" (en AA.VV. 1992: 168).

Ángeles del vacío, el dúo Campos/Malevitch trae el anuncio de la inmanencia y de la desnudez. Cómo lograr el júbilo con objetos inertes (incluido el cuerpo): el mismo problema afrontaba Haroldo de Campos quien, no casualmente, denominó a los parangolés "ala delta para el éxtasis". El ala delta es, según la definición de la Federación Aeronáutica Internacional (FAI), "un planeador que puede ser transportado, despegado y aterrizado con la única ayuda de las piernas del piloto", o sea que al decir "ala delta para el éxtasis", Haroldo parece estar planteando que estas obras de Oiticica son una invención de planos de inmanencia para el goce. Un vuelo en el que sólo se necesita el impulso del propio cuerpo y de la capa. La misma definición cabe para las Galáxias que culminan con la experiencia de la epifanía de lo inmanente y del blanco sobre blanco. En 1976, Haroldo compone el "formante terminal", último texto de la serie, con las palabras "enquanto a mente quase-íris se emparadisa neste multilivro e della doppia danza". ${ }^{27}$ Construido con versos del Canto XIII y XXVIII del Paradiso de la Divina Commedia, la elección muestra el giro sustancial que recibe el paideuma haroldiano en esos años:

26. Definición tomada de internet (http://www.la-muela.com/aladelta2.htm).

27. La frase, construida con versos de Dante, también recuerda a Pound, quien definió la "logopeia" como "danza de las palabras ante el intelecto". En la anotación de la edición de Giuseppe Vandelli a la Divina Commedia se lee: "imparadisa: neologismo dantesco = esalta a gioie paradisache" (865). 
además de incorporar algunos autores inauditos desde el programa concretista (como Novalis, eje de Signantia: quasi coelum de 1979, u Octavio Paz con Transblanco, de 1985), Haroldo comienza su avance sobre los autores canónicos y en cierto modo sagrados de la cultura occidental: la Divina Commedia, el Fausto de Goethe, la Ilíada, la Biblia. No se trata estrictamente de traducciones porque son - como lo ha teorizado el propio autor transcreaciones y también porque son profanaciones en por lo menos dos sentidos: impugnan la traducción con fines religiosos instrumentales (lo que sucede básicamente con los textos bíblicos) y reabren la experiencia de aquello que hasta entonces había permanecido inaccesible por excelso. ${ }^{28}$ Con Pedra e Luz na Poesia de Dante, Haroldo cercena el Paradiso y asume la persona de Dante en una reinvención de su propia lengua. En las Galáxias va más lejos aún: cierra su propio viaje entre la lengua y el afuera con los versos del Paradiso como si su epifanía pudiera homologarse a la del poeta fiorentino. Esa experiencia paradisíaca (la mente quase-íris que se emparadisa), ya no remite a un origen sino que es la delicia - el edén - del presente, de la fala. El nombre que asume esta experiencia del éxtasis en la inmanencia es, una vez más, el blanco sobre blanco.

Pound, num esplêndido tour de force, lê compriso bianco no sentido de "compreendido no seu todo", clarificado por uma luz total ("todas as cores unidas no branco"), remetendo ao verbo imbiancare, usado por Dante no Paradiso [...] Transculturação sincrônica. Maliévich: branco no branco (Haroldo de CAmpos 1998: 72).

El entre del trazo blanco (el "entre/inter-") produce la blancura extática paradisíaca como resultado de un largo trabajo poético (recordemos la autodescripción del proceso hacia la epifanía que hizo el propio autor). No es el blanco como ausencia de color sino como suma de todos ellos. Es por esto que el paraíso haroldiano se nutre de la poesía de Dante como presencia configuradora de sentido paradisíaco o epifánico. Sin embargo, este paraíso no es una realidad trascendente sino una iluminación inmanente que surge en el momento en que lengua y pensamiento devienen galaxia, constelación. ${ }^{29}$

28. En Pedra e Luz na Poesia de Dante Haroldo habla de "tradução luciferina" (15).

29. Desarrollo estas cuestiones en Aguilar 2005. 
La cuestión del blanco como lugar de la aparición y de la desaparición, como experiencia sublime de suma, también está - según la lectura de Oiticica en la poesía de Augusto de Campos. Sobre todo en Poetamenos, que comienza a ser releído en 1973 bajo nuevas condiciones a partir de la edición conmemorativa que se hace por los treinta años de su publicación. En una de las cintas que grabó dedicadas a Augusto, el 19 de marzo de 1974, Hélio hace una lectura del poema "dias dias dias":

eu acho que o branco... bom uma coisa louca que eu descobrí quando tem aquele negócio: "a" e depois "mor" é "amor", mas é "morte", mas aí você nunca... a gente fica assim imediatamente completando "mor", com morte mas a sílaba "T-E" na realidade o branco tá cobrindo ela é a meu ver a gente tem muita dessa coisa assim do pó aparecer e desaparecer nesse... quer dizer é tudo como se fosse assim uma espécie de exercício assim da ambivalência da pessoa... sei lá aliás o branco dessa coisa tem uma coisa assim de neve um pouco de neve de neve também já é cocaína "snow" essa coisa assim [...] não é livro são assim espaços filmicos, Blocos-espaços-filmicos.

Hélio Oiticica lee -en una dialéctica del cubrir y descubrir- una sílaba que no está, que estaría oculta en el blanco o en lo que imagina la nieve de la cocaína. La operación, de todos modos, está avalada por el poema "Amortemor" de Augusto en el que se lee la serie: amor - morte - temor - aire. En "dias, dias dias", el amor sería el trazo (en color rojo) y la muerte, el plegado del blanco.

Hélio Oiticica está leyendo las Galáxias y Poetamenos desde Malevitch y Nietzsche, que era un lectura a la que fue fiel durante todos esos años pasados en Nueva York. En una de las cintas que le grabó a Augusto de Campos afirma nietzcheanamente: "o corpo sabe mais [...] é a desligação total da terra, é a descoberta do corpo porque ele esqueceu a terra, então qualquer pessoa dança" (Fita "Para Augusto de Campos", 1ํ de marzo de 1974, subrayado mío). ¿Qué puede un cuerpo? dijo Spinoza. ¿Qué podemos saber de esa figura extravagante que es nuestro cuerpo? se preguntó Valéry. Hélio Oiticica encuentra un saber del cuerpo donde menos se lo esperaba: en la poesía supuestamente fría y cerebral de los poetas de Noigandres. Si en los sesenta su arte había encontrado ese saber en el cuerpo popular heroico o danzante, en los setenta se orienta hacia ese nuevo sublime del cuerpo velado y desnudo que ve concretado en lo sensible de la página en blanco. El trazo 
blanco une lo visible y lo no visible, condensa aquello que está separado y es imposible de representar: es la materia misma que, desnuda, está en éxtasis, en el "éxtasis de lo discontinuo" como dijo Hélio o en el "júbilo de los objetos" como escribió Haroldo.

Resumén: En este texto se investigan las relaciones ente el artista plástico Hélio Oiticica y los poetas del grupo Noigandres: Décio Pignatari, Haroldo y Augusto de Campos. A partir de la correspondencia y de algunas obras artísticas y poemas, se considera la cuestión del "blanco sobre blanco" como un punto de confluencia y de experimentación que comparten estos artistas durante la década del setenta.

Palabras claves: concretismo, Hélio Oiticica, "Blanco sobre blanco".

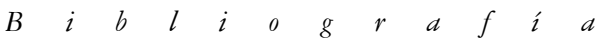

AA.VV. (1992): Hélio Oiticica, Barcelona, Fundació Antoni Tàpies.

AGUILAR, Gonzalo (2005): Poesia concreta brasileira: as vanguardas na encruzilhada modernista, São Paulo, Edusp.

AGUILAR, Gonzalo (2005): "Hélio Oiticica: la invención del espacio", en Punto de Vista, número 84, abril.

ALIGHIERI, Dante (1983): La Divina Commedia, Milano, Ulrico Hoepli.

AMARAL, Aracy (1977): Projeto construtivo brasileiro na arte (1950-1962), Rio de Janeiro: MEC/Funarte.

BENJAMIN, Walter (1990): El origend el drama barroco alemán, Madrid, Taurus.

BERSANI, Leo (1986): The Freudian Body (Psychoanalysis and Art), New York, Columbia University Press.

CAMPOS, Haroldo (1984): Galáxias, São Paulo, Ex Libris.

CAMPOS, Haroldo de (1994): Hagoromo de Zeami (O charme Sutil), com uma colaboração especial de Darci Yasuco Kusano e Elza Taeko Doi, São Paulo, Estação Liberdade.

CAMPOS, Haroldo de (1998): Pedra e Luz na Poesia de Dante, Rio de Janeiro, Imago, primera edición de 1978.

CAMPOS, Haroldo de (2004): Éden (Um tríptico bíblico), São Paulo, Perspectiva.

CAMPOS, Haroldo de (2006): "Hélio Oiticica: el músico de la materia" en Del arco iris blanco, Buenos Aires, Adriana Hidalgo.

CAMPOS, Augusto de y Haroldo de (2002): Re visão de Sousândrade, $3^{\text {a }}$ edição revisada e aumentada, São Paulo, Perspectiva.

CAMPOS, Augusto de (1973): Poetamenos, San Pablo, Invenção, primera edición de 1953. 
CARDOSO, Ivan (2002): De Godard a Zé do Caixão, Rio de Janeiro, Funarte.

DELEUZE, Gilles (1987): Foucault, Buenos Aires, Paidós.

DERRIDA, Jacques (1975): “La doble sesión” en La diseminación, Madrid, Fundamentos.

FIGUEIREDO, Luciano, curadoria (2002): Hélio Oiticica: Obra e estratégia, Rio de Janeiro, Museu de Arte Moderna.

FOUCAULT, Michel (1980): La verdad y las formas jurídicas, Buenos Aires, Gedisa.

FOUCAULT, Michel (1985): El discurso del poder, presentación y selección de Oscar Terán, Buenos Aires, Folios.

LYOTARD, Jean-François (1998): Lo inhumano (Charlas sobre el tiempo), Buenos Aires, Manantial.

MENDES, Murilo (1980): "Texto branco" en Transístor (Antologia de Prosa 19311974), Rio de Janeiro, Nova Fronteira.

NESTLE, Wilhelm (1981): Historia del espíritu griego (Desde Homero hasta Luciano), Barcelona, Ariel.

NIETZSCHE, Federico (1980): La voluntad de poderío, Madrid, Edaf.

OITICICA, Hélio (1986): Aspiro ao grande labirinto, Rio de Janeiro, Rocco.

PIGNATARI, Décio (1995): Letras, artes, mídia, São Paulo, Globo.

PIGNATARI, Décio (1975): Teoria da poesia concreta (Textos críticos e manifestos 19501960), São Paulo, Duas Cidades.

POUND, Ezra (1975): Cantares completos, México, Joaquín Mortiz.

SCIGLIANO CARNEIRO, Beatriz (2004): Relâmpagos com claror (Lygia Clark e Hélio Oiticica, vida como arte), São Paulo, Fapesp.

$$
\begin{array}{llllllllllllllllllll}
I & l & u & s & t & r & a & c & i & 0 & n & e & s
\end{array}
$$

Ilust.1: Portada de la revista Navilouca (Almanaque dos Aqualoucos) de 1974.

Ilust.2: "O 'Rock n'Roll' da poesia" en la revista O Cruzeiro, 2 de marzo de 1957. En las fotos se puede ver a Ferreira Gullar, Haroldo y Augusto de Campos y Hélio Oiticica, entre otros.

Ilust.3: "Agripina é Roma-Manhattan”, ideograma de Hélio Oiticica.

Ilust.4: Inscripción $M$ 'Way Ke en el parangolé dedicado a Haroldo de Campos.

Ilust.5: Luis Fernando Guimarães con Parangolé, capa 23 M'Way Ke, foto tomada en 1972 en Nueva York.

Ilust.6: Omar viste el Parangolé, capa 23 M’Way Ke.

Ilust. 7: Reproducción de la foto enviado por Hélio Oiticica a Haroldo de Campos en el libro Hagoromo de Zeami.

Ilust.8: Jeff viste el parangolé 31, capa 24.

Ilust.9: Parangolé Somethin'Fa'the Head que incluye una comparación entre Poetamenos de Augusto de Campos y Blanco sobre blanco de Malévitch. 


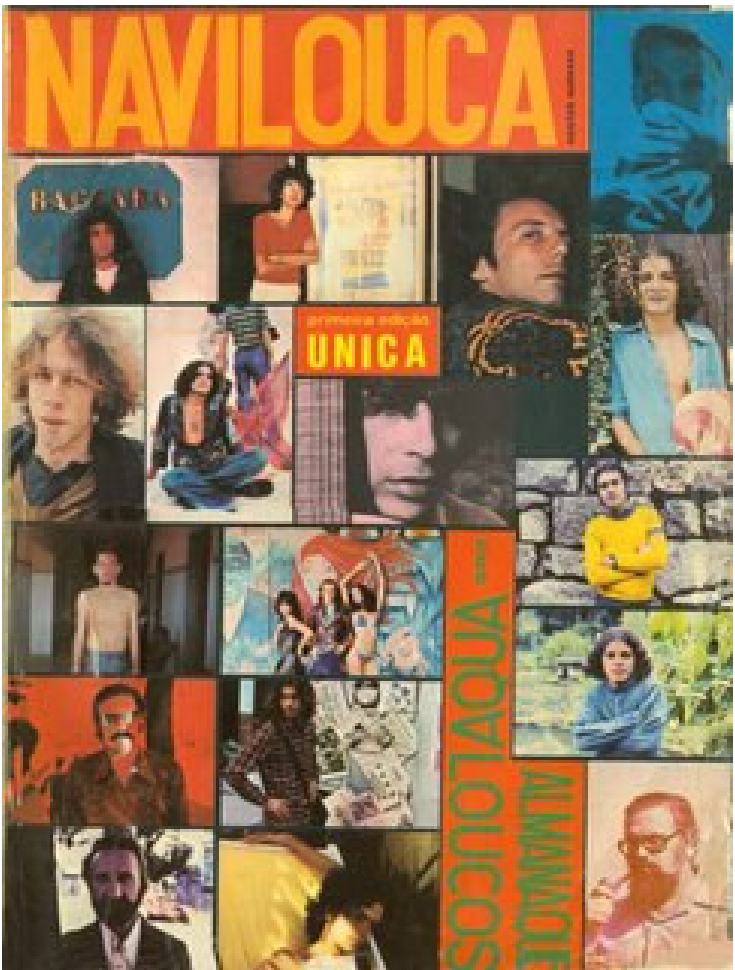

ILUST. 1: Portada de la revista Navilouca (Almanaque dos Aqualoucos) de 1974.

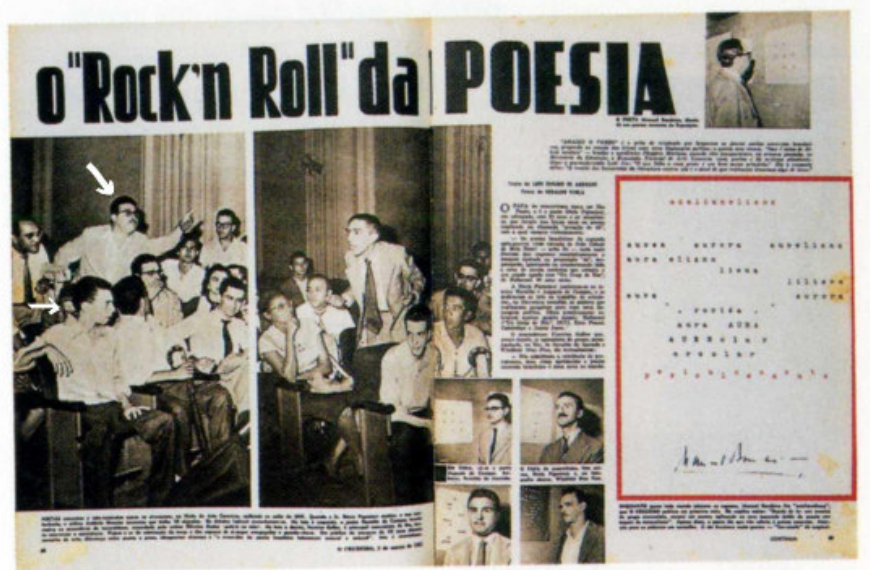

ILUST. 2: "O 'Rock n'Roll' da poesia" en la revista O Cruzeiro, 2 de marzo de 1957. En las fotos se puede ver a Ferreira Gullar, Haroldo y Augusto de Campos y Hélio Oiticica, entre otros. 
Belo Horizonte, p. 1-232

Disponível em: bttp://www.letras.ufmg.br/poslit

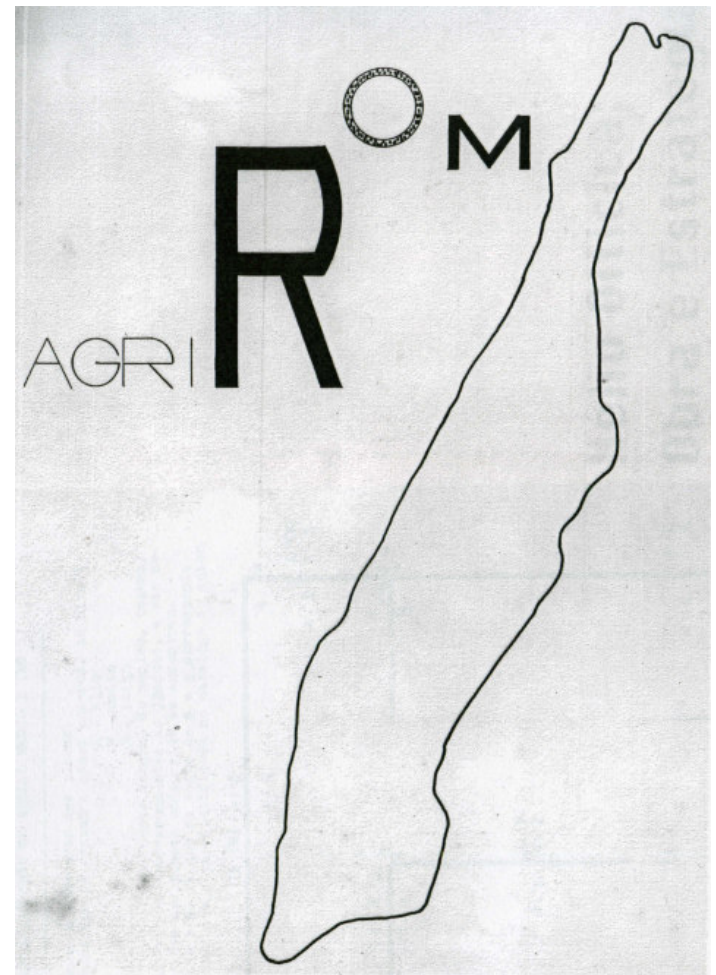

ILUST. 3: "Agripina é Roma-Manhattan”, ideograma de Hélio Oiticica.

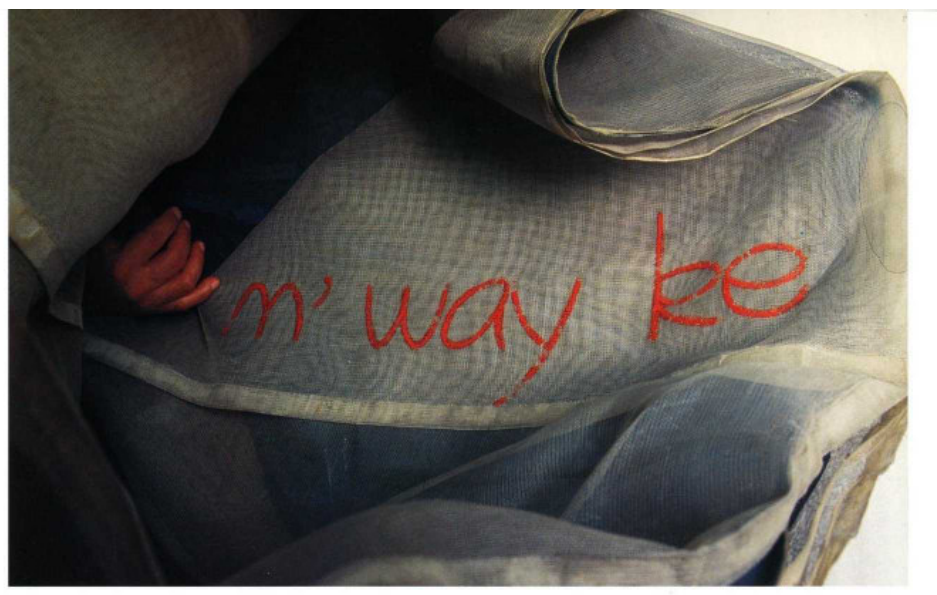

ILUST. 4: Inscripción $M^{\prime}$ Way Ke en el parangolé dedicado a Haroldo de Campos. 


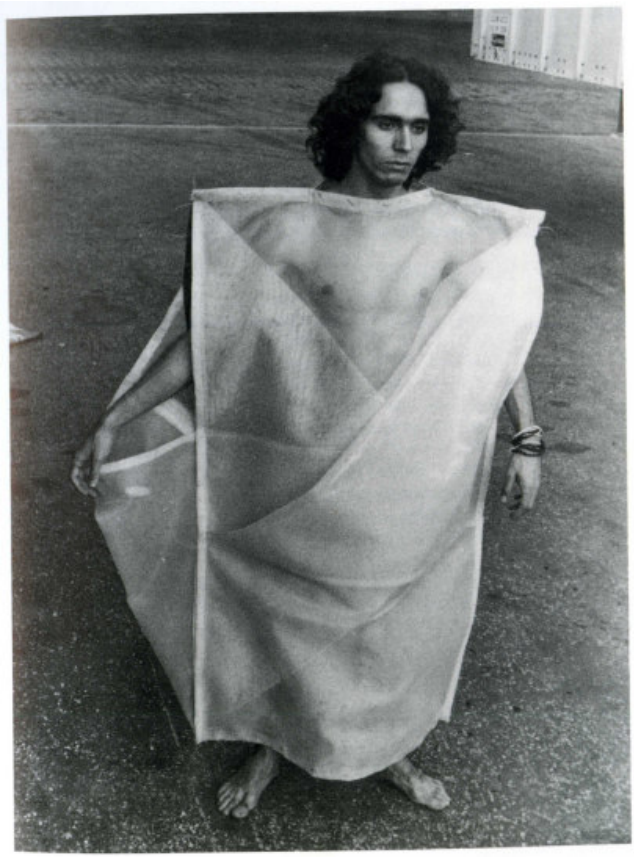

ILUST. 5: Luis Fernando Guimarães con Parangolé, capa 23 M'Way Ke, foto tomada en 1972 en Nueva York.

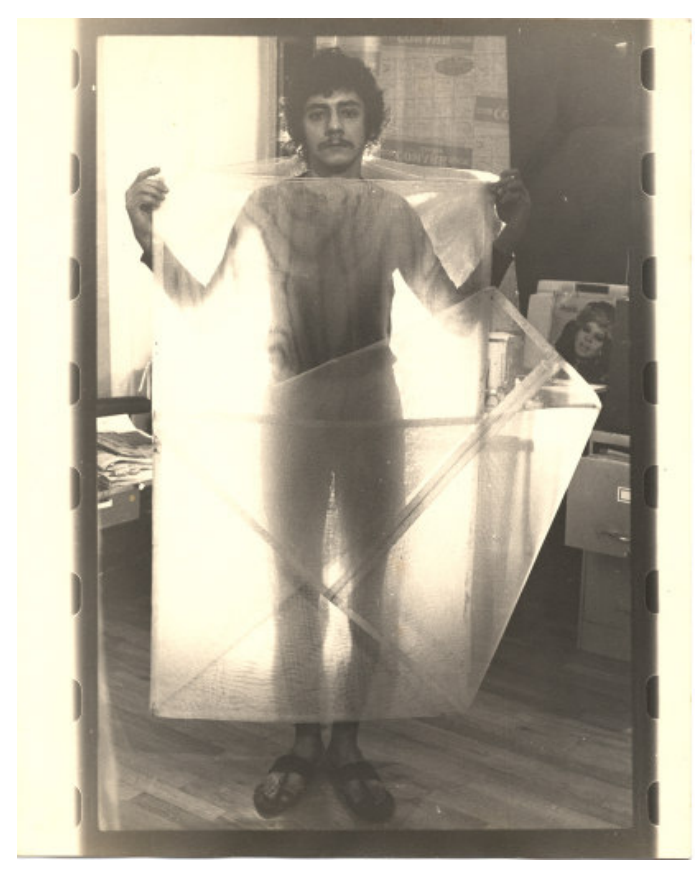

ILUST. 6: Omar viste el Parangolé, capa 23 M'Way Ke. 


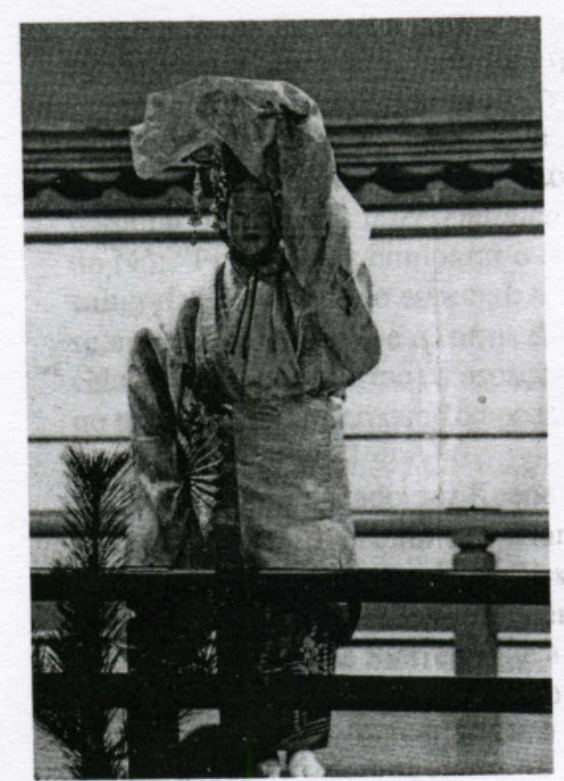

A Tennin com o Hagoromo ("Manto de Plumas")

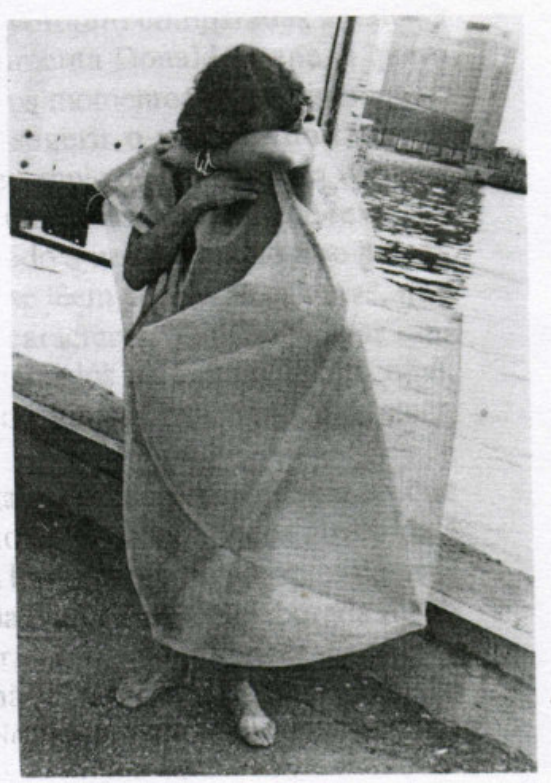

Parangolé (1965/72), de Hélio Oiticica, vestido pelo ator Luís Fernando; foto enviada ao Autor, com a dedicatória: "Para Haroldo, hagorômico em homenagem, 3.9.72." A foto foi realizada por H.O. em Nova Iorque, perto do pier 42 .

ILUST. 7: Reproducción de la foto enviado por Hélio Oiticica a Haroldo de Campos en el libro Hagoromo de Zeami. 


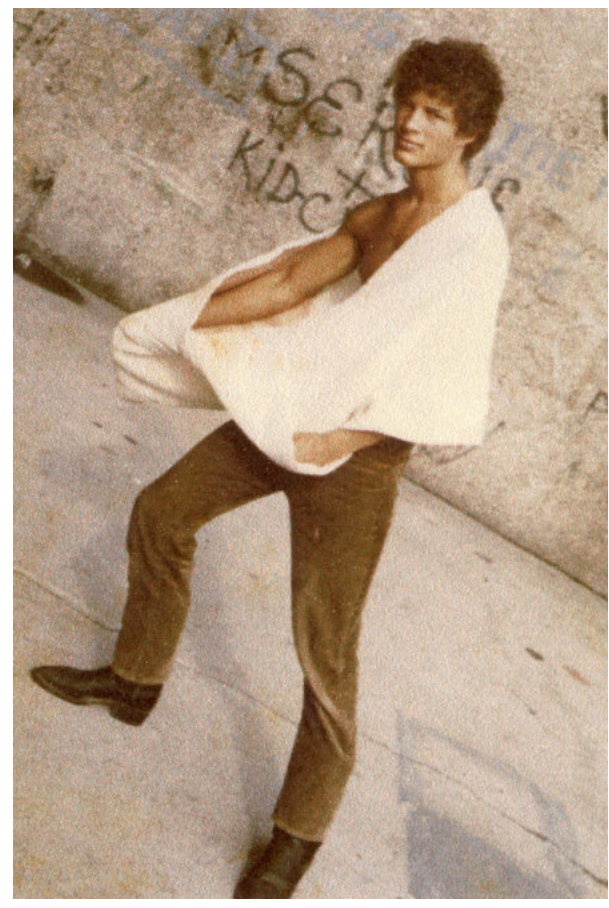

ILUST. 8: Jeff viste el parangolé 31, capa 24.

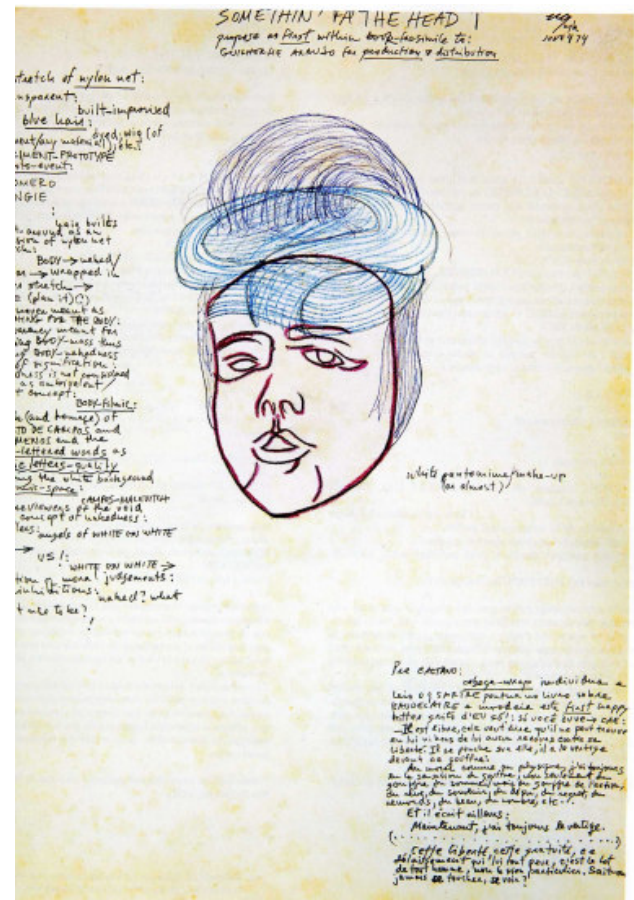

ILUST. 9: Parangolé Somethin'Fa'the Head que incluye una comparación entre Poetamenos de Augusto de Campos y Blanco sobre blanco de Malévitch. 